\title{
Kinetoplastid membrane protein-11 as a vaccine candidate and a virulence factor in Leishmania
}

\author{
Sergio Coutinho Furtado de Mendonça ${ }^{1 *}$, Léa Cysne-Finkelstein ${ }^{1}$ and \\ Denise Cristina de Souza Matos²
}

${ }^{1}$ Laboratório de Imunoparasitologia, Instituto Oswaldo Cruz, Fundação Oswaldo Cruz, Rio de Janeiro, Brazil, ${ }^{2}$ Laboratório de Tecnologia Imunológica, Instituto de Tecnologia em Imunobiológicos, Fundação Oswaldo Cruz, Rio de Janeiro, Brazil

\section{OPEN ACCESS}

Edited by: Alexandre Morrot,

Federal University of Rio de Janeiro,

Brazil

Reviewed by:

Marisa Mariel Fernandez, University of Buenos Aires, Argentina Celio Geraldo Freire De Lima, Federal University of Rio de Janeiro,

Brazil

*Correspondence:

Sergio Coutinho Furtado de Mendonça

mendonca@ioc.fiocruz.br

Specialty section: This article was submitted to Microbial Immunology, a section of the

journal Frontiers in Immunology

Received: 02 September 2015 Accepted: 25 September 2015

Published: 13 October 2015

Citation:

de Mendonça SCF,

Cysne-Finkelstein $L$ and Matos DCS

(2015) Kinetoplastid membrane protein-11 as a vaccine candidate and a virulence factor in Leishmania.

Front. Immunol. 6:524.

doi: 10.3389/fimmu.2015.00524
Kinetoplastid membrane protein-11 (KMP-11), a protein present in all kinetoplastid protozoa, is considered a potential candidate for a leishmaniasis vaccine. In Leishmania amazonensis, KMP-11 is expressed in promastigotes and amastigotes. In both stages, the protein was found in association with membrane structures at the cell surface, flagellar pocket, and intracellular vesicles. More importantly, its surface expression is higher in amastigotes than in promastigotes and increases during metacyclogenesis. The increased expression of KMP-11 in metacyclic promastigotes, and especially in amastigotes, indicates a role for this molecule in the parasite relationship with the mammalian host. In this connection, we have shown that addition of KMP-11 exacerbates L. amazonensis infection in peritoneal macrophages from BALB/c mice by increasing interleukin (IL)-10 secretion and arginase activity while reducing nitric oxide production. The doses of KMP-11, the IL-10 levels, and the intracellular amastigote loads were strongly, positively, and significantly correlated. The increase in parasite load induced by KMP-11 was inhibited by anti-KMP-11 or anti-IL-10-neutralizing antibodies, but not by isotype controls. The neutralizing antibodies, but not the isotype controls, were also able to significantly decrease the parasite load in macrophages cultured without the addition of KMP-11, demonstrating that KMP-11-induced exacerbation of the infection is not dependent on the addition of exogenous KMP-11 and that the protein naturally expressed by the parasite is able to promote it. All these data indicate that KMP-11 acts as a virulence factor in $L$. amazonensis infection.

Keywords: Leishmania, leishmaniasis, KMP-11, virulence factor, vaccine, Leishmania amazonensis, Leishmania braziliensis

\section{THE LEISHMANIASES}

Diversity is the key word for defining the leishmaniases, a group of diseases caused by the infection with parasitic protozoa of the genus Leishmania and transmitted by sandfly (Phlebotominae) vectors (1): diversity of parasite species, diversity of vector species, diversity of eco-epidemiological conditions involved in transmission, and diversity of clinical presentations. The leishmaniasis can be broadly classified as tegumentary (2), in which the parasitism is restricted to the integument (skin 
or mucosa) and visceral leishmaniasis (VL), in which internal organs like spleen, liver, bone marrow, and lymph nodes are infected. The former can be further divided into cutaneous (CL), diffuse cutaneous (DCL), and mucosal (or mucocutaneous, ML) leishmaniasis (1), according to clinical and immunopathological patterns. CL is the primary clinical form in all cases. It can be caused by all the dermotropic Leishmania parasites and it is, by far, the most common presentation of tegumentary leishmaniasis. ML and DCL are less frequent and more severe clinical forms, associated with distinct species and particular patterns of immune response. VL is caused by only two Leishmania species: Leishmania donovani and Leishmania infantum (3), but many species, belonging to two different subgenera (Leishmania and Viannia), can produce tegumentary leishmaniasis (1). While Old World CL is caused by three species, all of them of the Leishmania subgenus, American tegumentary leishmaniasis, so called because it encompasses CL, DCL, and ML, can be caused by various species of the Leishmania and the Viannia subgenera, the latter been exclusive of the American continent. It is currently estimated an annual incidence of 0.2-0.4 and 0.7-1.2 million cases for VL and CL cases, respectively, with a tentative estimate of 20,000-40,000 deaths per year due to VL. However, all these numbers are probably underestimated. Six countries (India, Bangladesh, Sudan, South Sudan, Ethiopia, and Brazil) account for more than $90 \%$ of global VL cases. CL has a wider geographical distribution, with the Americas, the Mediterranean basin, and western Asia being the most affected regions (4).

\section{CONTROL OF LEISHMANIA INFECTION BY THE MAMMALIAN IMMUNE SYSTEM}

There are two major morphological stages in the life cycle of Leishmania: the promastigote and the amastigote. The promastigotes are the 15-20 $\mu \mathrm{m}$ long flagellated and motile forms found within the insect vectors, while the 3-5 $\mu \mathrm{m}$ long amastigotes, which lack the external flagellum, are found inside mononuclear phagocytic cells of the mammalian hosts (5).

The promastigotes undergo a differentiation process termed metacyclogenesis within the gut of the insect vector (6). Metacyclic promastigotes are the infective form for the mammalian host. They have been shown to be far more resistant to complementmediated lysis than the procyclic promastigotes, which divide attached to the vector's midgut epithelial cells (7). After the inoculation of the infective promastigotes by the sandfly bite, the establishment of the intracellular infection depends on a number of factors: size of inoculum (8); the phlebotomine saliva, which contains immunomodulatory molecules (9); presence of apoptotic promastigotes (10), and, especially, the ability of the parasites to survive the innate immune response of the host, which includes, among other factors, complement-mediated lysis and opsonization, phagocytosis by neutrophils and macrophages, Toll-like receptors, the NLRP3 inflammasome, and many cytokines and chemokines (11). The successful establishment of the infection results in the amastigotes dividing in phagolysosomes of macrophages, where they inhibit or subvert the killing mechanisms of these cells, making them permissive to the infection (12).
At this point, the control of the infection will depend on the adaptive immune response. Th1 $\mathrm{CD}^{+}$cells induce the activation of the parasitized macrophages through the secretion of interferon-gamma (IFN- $\gamma$ ) (13), with the help of other proinflammatory cytokines, such as tumor necrosis factor-alpha (14), rendering these cells capable to kill the amastigotes by producing nitric oxide (NO) and/or reactive oxygen species (ROS) (15). The generation of an effective memory T-cell response is the goal of vaccination.

\section{THE SEARCH FOR A VACCINE AGAINST LEISHMANIASIS}

The transmission of pathogenic Leishmania species is characterized by a high degree of parasite-vector specificity (16) and 30 sandfly species are believed to be competent vectors (17). Each species has a particular ecology (18), which determines the transmission conditions and the risk factors for acquiring the disease. This diversity makes the design of control strategies extremely difficult. Moreover, the current control measures directed toward vectors and animal reservoirs have not been reliably effective (19). As a result, the geographical distribution of leishmaniasis is expanding, even to urban areas (20). On the other hand, the currently used chemotherapy regimens are toxic and expensive. Most of them have to be used parenterally for long periods (21), making adherence to therapy difficult to achieve (22). In addition, resistance to standard therapy, as pentavalent antimonials, is becoming more frequent (23). Therefore, an effective and safe vaccine could be the most comprehensive and cost-effective tool for the prevention of leishmaniasis (24).

There is no effective vaccine against any form of human leishmaniasis (24). However, during the last four decades, there have been many approaches for the development of a vaccine against leishmaniasis. Most of them stopped at the experimental level. Only a few have reached clinical trials. The majority of these were the so-called first-generation vaccine (25) candidates, composed of killed promastigotes. A major advantage of these vaccines is that they could be manufactured at low technological level and relative low cost in endemic countries (25). However, standardization of vaccines derived from cultured parasites would be impossible. Furthermore, after the various clinical trials performed with these vaccines, their efficacy has not been clearly demonstrated (26). The second-generation vaccine candidates encompass a variety of approaches: recombinant proteins, DNA, and genetically engineered organisms, such as vectored vaccines and attenuated Leishmania. As a rule, recombinant DNA technology is involved in their production. Their main advantages relate to safety and standardization because in this kind of vaccine, the content is precisely known. The immunization strategies mentioned above represent different modes of delivery of defined immunogens, which are, in general, parasite molecules. A number of them have been proposed as vaccine candidates, such as glycoprotein gp63, Leishmania homolog of receptors for activated $\mathrm{C}$ kinase (LACK), kinetoplastid membrane protein-11 (KMP-11), histone H1, sterol 24-c-methyltranferase, amastigotespecific protein A2, cysteine proteinases, nucleoside hydrolase, 
thiol-specific antioxidant, Leishmania major stress-inducible protein 1, Leishmania elongation initiation factor, among others $(27,28)$. The latter three constitute a multi-subunit candidate vaccine, Leish-111F, the only recombinant candidate vaccine against leishmaniasis already tested in humans $(27,28)$, so far without evidence of efficacy.

\section{KINETOPLASTID MEMBRANE PROTEIN-11 AS A VACCINE CANDIDATE}

Kinetoplastid membrane protein-11 was discovered as a T cellreactive contaminant (29) in preparations of lipophosphoglycan, the most abundant macromolecule on the surface of the promastigote stage of Leishmania spp. (30). Since then, it has been considered as a promising candidate antigen for a vaccine against leishmaniasis. It has shown an immunoprotective effect in a variety of immunization protocols (31-34).

Kinetoplastid membrane protein-11 is a protein characteristic and specific of kinetoplastid protozoa (35). The KMP-11 coding genes and their products show a remarkably high degree of sequence homology among all Leishmania species of both subgenera. When KMP-11 gene sequences of L. (Viannia) panamensis, L. (Leishmania) infantum, and $L$. (L) donovani were compared, a homology of more than $95 \%$ was found among them, and only three amino acid changes were found when the corresponding deduced amino acid sequences were compared (36). On the other hand, this protein shows very low homology with human proteins (37). KMP-11 has a strong antigenicity for murine (31) and human T cells (38) and is capable of stimulating both innate (39) and adaptive (38) immune responses. All these are characteristics of an ideal leishmaniasis vaccine candidate.

Another fundamental aspect for a candidate antigen for a leishmaniasis vaccine is its expression in the amastigote, the infective stage for mammals. Concerning this subject, there are interesting reports on the variability of KMP-11 expression among different species of Leishmania. This protein was found to be expressed at higher levels in L. infantum promastigotes than in amastigotes $(40,41)$, whereas its expression is up-regulated in amastigotes of Leishmania amazonensis (42) and Leishmania mexicana (41). It is interesting to notice that these three species belong to the Leishmania subgenus. To our knowledge, a similar investigation on differential expression of KMP-11 in species belonging to the Viannia subgenus has never been performed. Recognizing this variability is necessary for the understanding of the diversity found in the infections with different Leishmania species with regard to host-parasite relationship and pathogenesis. Unfortunately, this aspect has been largely neglected in leishmaniasis research. It is possible that a molecule, which plays a key role in the infection with a given Leishmania species would have no relevance at all for another. In this sense, it is surprising that the genomes of species causing so diverse diseases in humans like L. major, L. infantum (both from the Leishmania subgenus) and Leishmania braziliensis (Viannia subgenus) contain $<1 \%$ species-specific genes (43). A possible explanation for this unexpected finding is that, in spite of the high similarity in their genome sequences, important differences were found between different Leishmania species with regard to stage-regulated gene expression (44). These differences may represent the adaptation to different vector species or the development of different strategies for survival in the mammalian host.

\section{IMMUNOLOGICAL BASIS FOR VIRULENCE FACTORS AS VACCINES AGAINST LEISHMANIASIS}

During several decades, a reductionist vision has oversimplified the understanding of immunopathology of the leishmaniases. This was based in conclusions drawn from the mouse model of L. major infection. In this model, there is an association of resistance or susceptibility to infection with the predominance of Th1 or Th $2 \mathrm{CD}^{+} \mathrm{T}$ cell-mediated responses, respectively (45). Although this model has contributed to demonstrate the key role played by IFN- $\gamma$ and Th1 cells in the control of Leishmania infection, it has become clear that the resistance/susceptibility to other Leishmania species do not fit into the so-called Th1/ Th2 paradigm (46). Nevertheless, it has long guided the efforts of immunoparasitologists and vaccinologists toward the development of an anti-Leishmania vaccine. During this period, the Th1/Th2 paradigm was the conceptual basis for the search of potentially protective candidate antigens for a vaccine against leishmaniasis. However, this strategy eventually proved to be ineffective. Leishmania antigens that stimulate a Th1 immune response during the disease or even after cure were not able to induce protection when used as vaccines. On the other hand, antigens associated with disease-promoting immune responses in the early infection have been found to be highly protective if a Th1 response to them is generated by vaccination before infection (47). Probably, the best example of this is the LACK antigen which stimulates a strong Th2 response soon after infection of BALB/c mice (48) that is responsible for their extreme susceptibility to this parasite (49). However, the same antigen, when administered with adjuvants that stimulate Th1 responses (50) or as a DNA vaccine (51) protects BALB/c mice from subsequent infections with L. major. During coevolution, parasites have learned how to manipulate the host immune system to their own advantage by developing particular ways of antigen presentation and delivery during infection. Based on accumulating evidence, it is reasonable to believe that those evasion strategies can be overcome by defined immunization protocols using disease-promoting parasite antigens. Thus, at present, virulence factors are considered as potential drug targets and vaccine candidates for the control of leishmaniasis (52) and other infectious diseases (53).

\section{KINETOPLASTID MEMBRANE PROTEIN-11 AS A VIRULENCE FACTOR IN LEISHMANIA SPP.}

It has been shown that KMP-11 is a potent inducer of interleukin-10 (IL-10) production in peripheral blood mononuclear 
cells from patients with American CL and it is also able to inhibit the IFN- $\gamma$ response of these cells to soluble $L$. braziliensis antigen extract $(54,55)$. IL-10 is a cytokine with anti-inflammatory properties produced by $\mathrm{T}$ cells, B cells, macrophages/monocytes, and keratinocytes. It can inhibit the synthesis of proinflammatory cytokines and chemokines as well as the production of NO and ROS by macrophages (56-58), restraining their ability to kill intracellular organisms (59-62).

Mukhopadhyay et al. suggested that KMP-11 may play a role in the virulence of $L$. donovani promastigotes because the loss of infective power obtained by successive sub-culturing was associated with a down-regulation of its expression (63).

Moreover, the increased expression of KMP-11 in metacyclic promastigotes, and especially in amastigotes, indicates a role for this molecule in the parasite relationship with the mammalian host, at least in members of the L. mexicana complex (64): L. amazonensis (42) and L. mexicana (41).

All these observations have prompted us to investigate a possible role for KMP-11 as a virulence factor in Leishmania. By using an in vitro model, we showed an exacerbating effect of KMP-11 on the infection of peritoneal macrophages from $\mathrm{BALB} / \mathrm{c}$ mice with $L$. amazonensis, implicating this protein as a virulence factor for this species. This effect was higher when KMP-11 was added to the cultures $4 \mathrm{~h}$ after infection (and after the removal of the remaining extracellular promastigotes), as compared to simultaneously or $4 \mathrm{~h}$ before infection, demonstrating that the infection-promoting effect of the protein was on amastigote proliferation rather than on the internalization of promastigotes. The increase in amastigote loads was associated to an increase in IL-10 secretion and arginase activity and to an inhibition of NO production. More importantly, anti KMP-11 and anti-IL-10 antibodies were able to significantly decrease the parasite load in macrophages cultured without the addition of KMP-11, demonstrating that KMP-11-induced exacerbation of the infection is not dependent on the addition of exogenous KMP-11 and that the protein naturally expressed by the parasite is able to promote it (65).

It was recently demonstrated that poly(lactide-co-glycolide acid) nanoparticles loaded with KMP-11 induce of potent innate responses in $\mathrm{BALB} / \mathrm{c}$ macrophages infected with L. braziliensis, promoting amastigote killing. These responses involve increased production of NO, superoxide, TNF- $\alpha$ and IL-6; release of CCL2/MCP-1 and CXCL1/KC; recruitment of macrophages and neutrophils in vitro; activation of caspase- 1 and the secretion of IL-1 $\beta$ and IL-18 (39). Interestingly, the recombinant protein alone did not show such an effect. In contrast to our work with L. amazonensis, which was performed with resident peritoneal macrophages (65), thioglycolate-activated macrophages were used in this study.

The results described obtained with soluble or PLGA-coupled KMP-11 in in vitro infections of resident or thioglycolateactivated $\mathrm{BALB} / \mathrm{c}$ peritoneal macrophages infected with $L$. amazonensis or $L$. braziliensis pose interesting questions concerning antigen delivery, macrophage activation, and differences in patterns of host-parasite relationship between different Leishmania species.

Leishmania amazonensis or L. braziliensis belong to different subgenera, Leishmania and Viannia, respectively (66), which are thought to have diverged 90 million years ago, when South America and Africa separated (67). Thus, New World $\mathrm{CL}$ is a disease caused by parasites that are quite different from each other. From the human health point of view, one of their most significant differences is the way that species from different subgenera interact with the mammalian host immunity (66).

Leishmania amazonensis and other members of the L. mexicana complex possess a remarkable ability to subvert or modulate innate and adaptive immune responses of the vertebrate host $(68,69)$. As a result of this, these parasites cause non-healing cutaneous lesions in most inbred strains of mice (68), although differences in susceptibility can be observed among them (69). In humans, L. amazonensis and L. mexicana are responsible for DCL, the only incurable form of human leishmaniasis, characterized by complete absence of specific type 1 response (proinflammatory, parasiticidal) to leishmanial antigens and unrestrained parasite growth (70).

Leishmania braziliensis and other species of the Viannia subgenus are not as able as the species of the L. mexicana complex to suppress proinflammatory and parasiticidal type 1 responses. Instead, the disease occurs in presence of an established Th1 response and IFN- $\gamma$ production. Nevertheless, this response has some inhibitory effect on parasite growth. That is why parasites are less numerous in cutaneous lesions caused by L. braziliensis than in those produced by infection with L. amazonensis (66). The severe clinical form resulting from L. braziliensis is ML, which is associated with up-regulated Th1 responses (71). L. braziliensis is much less pathogenic for mice than L. amazonensis. Experimental infection with $L$. braziliensis can only be achieved in the BALB/c strain $(72,73)$.

\section{CONCLUSION AND PERSPECTIVES}

The presented data indicate that KMP-11 can act as a virulence factor for L. amazonensis, although this may not be the case for other Leishmania species. Future research on this subject should include the demonstration of an in vivo disease-exacerbating effect of KMP-11 in leishmanial infection and the evaluation of the role played by this molecule in the infection with other Leishmania species.

\section{ACKNOWLEDGMENTS}

The studies performed by the authors were supported by grants from Conselho Nacional de Desenvolvimento Científico e Tecnológico (CNPq) and Fundação de Amparo à Pesquisa do Estado do Rio de Janeiro (FAPERJ). We would also like to thank Daniel Lacerda and Lanuza Faccioli, who were supported by $\mathrm{CNPq}$ fellowships, for their relevant contributions to these studies. 


\section{REFERENCES}

1. Kevric I, Cappel MA, Keeling JH. New world and old world Leishmania infections: a practical review. Dermatol Clin (2015) 33(3):579-93. doi:10.1016/j. det.2015.03.018

2. Escobar MA, Martinez F, Scott Smith D, Palma GI. American cutaneous and mucocutaneous leishmaniasis (tegumentary): a diagnostic challenge. Trop Doct (1992) 22(Suppl 1):69-78;63-4

3. Roatt BM, Aguiar-Soares RD, Coura-Vital W, Ker HG, Moreira ND, Vitoriano-Souza J, et al. Immunotherapy and immunochemotherapy in visceral leishmaniasis: promising treatments for this neglected disease. Front Immunol (2014) 5:272. doi:10.3389/fimmu.2014.00272

4. Alvar J, Vélez ID, Bern C, Herrero M, Desjeux P, Cano J, et al. WHO leishmaniasis control team. leishmaniasis worldwide and global estimates of its incidence. PLoS One (2012) 7(5):e35671. doi:10.1371/journal. pone.0035671

5. Pace D. Leishmaniasis. J Infect (2014) 69(Suppl 1):S10-8. doi:10.1016/j. jinf.2014.07.016

6. Sacks DL. Metacyclogenesis in Leishmania promastigotes. Exp Parasitol (1989) 69(1):100-3. doi:10.1016/0014-4894(89)90176-8

7. Descoteaux A, Turco SJ. Glycoconjugates in Leishmania infectivity. Biochim Biophys Acta (1999) 1455(2-3):341-52. doi:10.1016/S0925-4439(99)00065-4

8. Kimblin N, Peters N, Debrabant A, Secundino N, Egen J, Lawyer P, et al. Quantification of the infectious dose of Leishmania major transmitted to the skin by single sand flies. Proc Natl Acad Sci U S A (2008) 105(29):10125-30. doi:10.1073/pnas.0802331105

9. Gillespie RD, Mbow ML, Titus RG. The immunomodulatory factors of bloodfeeding arthropod saliva. Parasite Immunol (2000) 22(7):319-31. doi:10.1046/j.1365-3024.2000.00309.x

10. Wanderley JL, Pinto da Silva LH, Deolindo P, Soong L, Borges VM, Prates $\mathrm{DB}$, et al. Cooperation between apoptotic and viable metacyclics enhances the pathogenesis of Leishmaniasis. PLoS One (2009) 4(5):e5733. doi:10.1371/ journal.pone.0005733

11. Gurung P, Kanneganti TD. Innate immunity against Leishmania infections. Cell Microbiol (2015) 17(9):1286-94. doi:10.1111/cmi.12484

12. Vannier-Santos MA, Martiny A, de Souza W. Cell biology of Leishmania spp.: invading and evading. Curr Pharm Des (2002) 8(4):297-318. doi:10.2174/1381612023396230

13. Santos Cda S, Boaventura V, Ribeiro Cardoso C, Tavares N, Lordelo MJ, Noronha A, et al. CD8(+) granzyme B(+)-mediated tissue injury vs. CD4(+) IFN $\gamma(+)$-mediated parasite killing in human cutaneous leishmaniasis. J Invest Dermatol (2013) 133(6):1533-40. doi:10.1038/jid.2013.4

14. Green SJ, Crawford RM, Hockmeyer JT, Meltzer MS, Nacy CA. Leishmania major amastigotes initiate the L-arginine-dependent killing mechanism in IFN-gamma-stimulated macrophages by induction of tumor necrosis factor-alpha. J Immunol (1990) 145(12):4290-7.

15. Mukbel RM, Patten C Jr, Gibson K, Ghosh M, Petersen C, Jones DE. Macrophage killing of Leishmania amazonensis amastigotes requires both nitric oxide and superoxide. Am J Trop Med Hyg (2007) 76(4):669-75.

16. Killick-Kendrick R. Some epidemiological consequences of the evolutionary fit between leishmaniae and their phlebotomine vectors. Bull Soc Pathol Exot (1985) 78:747-55.

17. Desjeux P. Public health aspects and control. Clin Dermatol (1996) 14:417-23. doi:10.1016/0738-081X(96)00057-0

18. Rotureau B, Gaborit P, Issaly J, Carinci R, Fouque F, Carme B. Diversity and ecology of sand flies (Diptera: Psychodidae: Phlebotominae) in coastal French Guiana. Am J Trop Med Hyg (2006) 75(1):62-9.

19. Stockdale L, Newton R. A review of preventative methods against human leishmaniasis infection. PLoS Negl Trop Dis (2013) 7(6):e2278. doi:10.1371/ journal.pntd.0002278

20. Martins-Melo FR, Lima Mda S, Ramos AN Jr, Alencar CH, Heukelbach J. Mortality and case fatality due to visceral leishmaniasis in Brazil: a nationwide analysis of epidemiology, trends and spatial patterns. PLoS One (2014) 9(4):e93770. doi:10.1371/journal.pone.0093770

21. Sharifi I, FeKri AR, Aflatonian MR, Khamesipour A, Nadim A, Mousavi MR, et al. Randomised vaccine trial of single dose of killed Leishmania major plus BCG against anthroponotic cutaneous leishmaniasis in Bam, Iran. Lancet (1998) 351(9115):1540-3. doi:10.1016/S0140-6736(98)09552-X
22. Ribeiro MN, Pimentel MI, Schubach Ade O, Oliveira Rde V, Teixeira JL, Leite MP, et al. Factors associated to adherence to different treatment schemes with meglumine antimoniate in a clinical trial for cutaneous leishmaniasis. Rev Inst Med Trop Sao Paulo (2014) 56(4):291-6. doi:10.1590/ S0036-46652014000400004

23. Sundar S, Rai M. Advances in the treatment of leishmaniasis. Curr Opin Infect Dis (2002) 15(6):593-8. doi:10.1097/00001432-200212000-00007

24. Modabber F. Leishmaniasis vaccines: past, present and future. Int J Antimicrob Agents (2010) 36(Suppl 1):S58-61. doi:10.1016/j.ijantimicag.2010.06.024

25. Evans KJ, Kedzierski L. Development of vaccines against visceral leishmaniasis. J Trop Med (2012) 2012:892817. doi:10.1155/2012/892817

26. Noazin S, Khamesipour A, Moulton LH, Tanner M, Nasseri K, Modabber F, et al. Efficacy of killed whole-parasite vaccines in the prevention of leishmaniasis: a meta-analysis. Vaccine (2009) 27(35):4747-53. doi:10.1016/j. vaccine.2009.05.084

27. Kumar R, Engwerda C. Vaccines to prevent leishmaniasis. Clin Transl Immunology (2014) 3(3):e13. doi:10.1038/cti.2014.4

28. Coler RN, Reed SG. Second-generation vaccines against leishmaniasis. Trends Parasitol (2005) 21(5):244-9. doi:10.1016/j.pt.2005.03.006

29. Jardim A, Tolson DL, Turco SJ, Pearson TW, Olafson RW. The Leishmania donovani lipophosphoglycan T lymphocyte-reactive component is a tightly associated protein complex. J Immunol (1991) 147:3538-44.

30. McConville MJ, Schnur LF, Jaffe C, Schneider P. Structure of Leishmania lipophosphoglycan: inter- and intra-specific polymorphism in old world species. Biochem J (1995) 310:807-18. doi:10.1042/bj3100807

31. Ramírez JR, Gilchrist K, Robledo S, Sepúlveda JC, Moll H, Soldati D, et al. Attenuated Toxoplasma gondii ts- 4 mutants engineered to express the Leishmania antigen KMP-11 elicit a specific immune response in BALB/c mice. Vaccine (2001) 20(3-4):455-61. doi:10.1016/S0264-410X(01)00341-3

32. Basu R, Bhaumik S, Basu JM, Naskar K, De T, Roy S. Kinetoplastid membrane protein-11 DNA vaccination induces complete protection against both pentavalent antimonial-sensitive and -resistant strains of Leishmania donovani that correlates with inducible nitric oxide synthase activity and IL-4 generation: evidence for mixed Th1 - and Th2-like responses in visceral leishmaniasis. J Immunol (2005) 174(11):7160-71. doi:10.4049/jimmunol.174.11.7160

33. Bhaumik S, Basu R, Sen S, Naskar K, Roy S. KMP-11 DNA immunization significantly protects against $L$. donovani infection but requires exogenous IL-12 as an adjuvant for comparable protection against L. major. Vaccine (2009) 27(9):1306-16. doi:10.1016/j.vaccine.2008.12.053

34. Guha R, Das S, Ghosh J, Naskar K, Mandala A, Sundar S, et al. Heterologous priming-boosting with DNA and vaccinia virus expressing kinetoplastid membrane protein-11 induces potent cellular immune response and confers protection against infection with antimony resistant and sensitive strains of Leishmania (Leishmania) donovani. Vaccine (2013) 31(15):1905-15. doi:10.1016/j.vaccine.2013.02.025

35. Stebeck CE, Beecroft RP, Singh BN, Jardim A, Olafson RW, Tuckey C, et al. Kinetoplastid membrane protein-11 (KMP-11) is differentially expressed during the life cycle of African trypanosomes and is found in a wide variety of kinetoplastid parasites. Mol Biochem Parasitol (1995) 71:1-13. doi:10.1016/0166-6851(95)00022-S

36. Ramírez JR, Berberich C, Jaramillo A, Alonso C, Vélez IV. Molecular and antigenic characterization of the Leishmania (Viannia) panamensis kinetoplastid membrane protein-11. Mem Inst Oswaldo Cruz (1998) 93(2):247-54. doi:10.1590/s0074-02761998000200022

37. Jardim A, Hanson S, Ullman B, Mccubbin WD, Kayt CM, Olafson RW. Cloning and structure-function analysis of the Leishmania donovani kinetoplastid membrane protein-11. Biochem J (1995) 305:315-20. doi:10.1042/bj3050315

38. Russo DM, Turco SJ, Burns JM Jr, Reed SG. Stimulation of human T lymphocytes by Leishmania lipophosphoglycan-associated proteins. J Immunol (1992) 148(1):202-7.

39. Santos DM, Carneiro MW, de Moura TR, Soto M, Luz NF, Prates DB, et al. PLGA nanoparticles loaded with KMP-11 stimulate innate immunity and induce the killing of Leishmania. Nanomedicine (2013) 9(7):985-95. doi:10.1016/j.nano.2013.04.003

40. Berberich C, Machado G, Morales G, Carrillo G, Jiménez-Ruiz A, Alonso C. The expression of the Leishmania infantum KMP-11 protein is developmentally regulated and stage specific. Biochim Biophys Acta (1998) 1442:230-7. doi:10.1016/S0167-4781(98)00176-6 
41. Lynn MA, Marr AK, McMaster WR. Differential quantitative proteomic profiling of Leishmania infantum and Leishmania mexicana density gradient separated membranous fractions. J Proteomics (2013) 82:179-92. doi:10.1016/j. jprot.2013.02.010

42. Matos DC, Faccioli LA, Cysne-Finkelstein L, Luca PM, Corte-Real S, Armoa $\mathrm{GR}$, et al. Kinetoplastid membrane protein-11 is present in promastigotes and amastigotes of Leishmania amazonensis and its surface expression increases during metacyclogenesis. Mem Inst Oswaldo Cruz (2010) 105:341-7. doi:10.1590/S0074-02762010000300018

43. Lynn MA, McMaster WR. Leishmania: conserved evolution - diverse diseases. Trends Parasitol (2008) 24(3):103-5. doi:10.1016/j.pt.2007.11.006

44. Rochette A, Raymond F, Ubeda JM, Smith M, Messier N, Boisvert S, et al. Genome-wide gene expression profiling analysis of Leishmania major and Leishmania infantum developmental stages reveals substantial differences between the two species. BMC Genomics (2008) 9:255. doi:10.1186/1471-2164-9-25

45. Reiner SL, Locksley RM. Lessons from Leishmania: a model for investigations of CD4+ subset differentiation. Infect Agents Dis (1992) 1(1):33-42.

46. McMahon-Pratt D, Alexander J. Does the Leishmania major paradigm of pathogenesis and protection hold for new world cutaneous leishmaniases or the visceral disease? Immunol Rev (2004) 201:206-24. doi:10.1111/j.0105-2896.2004.00190.x

47. Campos-Neto A. What about Th1/Th2 in cutaneous leishmaniasis vaccine discovery? Braz J Med Biol Res (2005) 38(7):979-84. doi:10.1590/ S0100-879X2005000700001

48. Launois P, Maillard I, Pingel S, Swihart KG, Xénarios I, Acha-Orbea H, et al. IL-4 rapidly produced by $\mathrm{V}$ beta $4 \mathrm{~V}$ alpha $8 \mathrm{CD} 4+\mathrm{T}$ cells instructs Th2 development and susceptibility to Leishmania major in BALB/c mice. Immunity (1997) 6(5):541-9. doi:10.1016/S1074-7613(00)80342-8

49. Julia V, Rassoulzadegan M, Glaichenhaus N. Resistance to Leishmania major induced by tolerance to a single antigen. Science (1996) 274:421-3. doi:10.1126/science.274.5286.421

50. Mougneau E, Altare F, Wakil AE, Zheng S, Coppola T, Wang ZE, et al. Expression cloning of a protective leishmania antigen. Science (1995) 268:563-6. doi:10.1126/science.7725103

51. Gurunathan S, Sacks DL, Brown DR, Reiner SL, Charest H, Glaichenhaus N, et al. Vaccination with DNA encoding the immunodominant LACK parasite antigen confers protective immunity to mice infected with Leishmania major. J Exp Med (1997) 186(7):1137-47. doi:10.1084/jem.186.7.1137

52. Mottram JC, Coombs GH, Alexander J. Cysteine peptidases as virulence factors of Leishmania. Curr Opin Microbiol (2004) 7(4):375-81. doi:10.1016/j. mib.2004.06.010

53. Li S, Huang H, Rao X, Chen W, Wang Z, Hu X. Phenol-soluble modulins: novel virulence-associated peptides of staphylococci. Future Microbiol (2014) 9(2):203-16. doi:10.2217/fmb.13.153

54. de Carvalho LP, Soto M, Jerônimo S, Dondji B, Bacellar O, Luz V, et al. Characterization of the immune response to Leishmania infantum recombinant antigens. Microbes Infect (2003) 5(1):7-12. doi:10.1016/ S1286-4579(02)00051-5

55. Carvalho LP, Passos S, Dutra WO, Soto M, Alonso C, Gollob KJ, et al. Effect of LACK and KMP11 on IFN-gamma production by peripheral blood mononuclear cells from cutaneous and mucosal leishmaniasis patients. Scand J Immunol (2005) 61(4):337-42. doi:10.1111/j.1365-3083.2005.01581.x

56. Spits $\mathrm{H}$, de Waal Malefyt R. Functional characterization of human IL-10. Int Arch Allergy Immunol (1992) 99(1):8-15. doi:10.1159/000236329

57. Opal SM, Wherry JC, Grint P. Interleukin-10: potential benefits and possible risks in clinical infectious diseases. Clin Infect Dis (1998) 27(6):1497-507. doi:10.1086/515032

58. Moore KW, de Waal Malefyt R, Coffman RL, O'Garra A. Interleukin-10 and the interleukin-10 receptor. Annu Rev Immunol (2001) 19:683-765. doi:10.1146/ annurev.immunol.19.1.683
59. Frei K, Nadal D, Pfister HW, Fontana A. Listeria meningitis: identification of a cerebrospinal fluid inhibitor of macrophage listericidal function as interleukin 10. J Exp Med (1993) 178(4):1255-61. doi:10.1084/jem.178.4.1255

60. Reed SG, Brownell CE, Russo DM, Silva JS, Grabstein KH, Morrissey PJ. IL10 mediates susceptibility to Trypanosoma cruzi infection. J Immunol (1994) 153(7):3135-40.

61. Murray PJ, Wang L, Onufryk C, Tepper RI, Young RA. T cell-derived IL-10 antagonizes macrophage function in mycobacterial infection. J Immunol (1997) 158(1):315-21.

62. Kane MM, Mosser DM. The role of IL-10 in promoting disease progression in leishmaniasis. J Immunol (2001) 166(2):1141-7. doi:10.4049/ jimmunol.166.2.1141

63. Mukhopadhyay S, Sen P, Majumder HK, Roy S. Reduced expression of lipophosphoglycan (LPG) and kinetoplastid membrane protein (KMP)-11 in Leishmania donovani promastigotes in axenic culture. J Parasitol (1998) 84:644-7. doi: $10.2307 / 3284745$

64. Tschoeke DA, Nunes GL, Jardim R, Lima J, Dumaresq AS, Gomes MR, et al. The comparative genomics and phylogenomics of Leishmania amazonensis parasite. Evol Bioinform Online (2014) 10:131-53. doi:10.4137/ EBO.S13759

65. Lacerda DI, Cysne-Finkelstein L, Nunes MP, De-Luca PM, Genestra Mda S, Leon LL, et al. Kinetoplastid membrane protein-11 exacerbates infection with Leishmania amazonensis in murine macrophages. Mem Inst Oswaldo Cruz (2012) 107(2):238-45. doi:10.1590/S0074-02762012000200014

66. Silveira FT, Lainson R, Corbett CE. Clinical and immunopathological spectrum of American cutaneous leishmaniasis with special reference to the disease in Amazonian Brazil: a review. Mem Inst Oswaldo Cruz (2004) 99(3):239-51. doi:10.1590/S0074-02762004000300001

67. Fernandes AP, Nelson K, Beverley SM. Evolution of nuclear ribosomal RNAs in kinetoplastid protozoa: perspectives on the age and origins of parasitism. Proc Natl Acad Sci Evol (1993) 90:11608-12. doi:10.1073/pnas.90.24.11608

68. Soong L. Subversion and utilization of host innate defense by Leishmania amazonensis. Front Immunol (2012) 3:58. doi:10.3389/fimmu.2012.00058

69. Pereira BA, Alves CR. Immunological characteristics of experimental murine infection with Leishmania (Leishmania) amazonensis. Vet Parasitol (2008) 158(4):239-55. doi:10.1016/j.vetpar.2008.09.015

70. Azeredo-Coutinho RB, Conceição-Silva F, Schubach A, Cupolillo E, Quintella LP, Madeira MF, et al. First report of diffuse cutaneous leishmaniasis and Leishmania amazonensis infection in Rio de Janeiro State, Brazil. Trans R Soc Trop Med Hyg (2007) 101(7):735-7. doi:10.1016/j.trstmh.2007.01.005

71. Bacellar O, Lessa H, Schriefer A, Machado P, Ribeiro de Jesus A, Dutra WO, et al. Up-regulation of Th1-type responses in mucosal leishmaniasis patients. Infect Immun (2002) 70(12):6734-40. doi:10.1128/IAI.70.12.6734-6740.2002

72. Samuelson J, Lerner E, Tesh R, Titus R. A mouse model of Leishmania braziliensis braziliensis infection produced by coinjection with sand fly saliva. J Exp Med (1991) 173(1):49-54. doi:10.1084/jem.173.1.49

73. de Moura TR, Novais FO, Oliveira F, Clarêncio J, Noronha A, Barral A, et al. Toward a novel experimental model of infection to study American cutaneous leishmaniasis caused by Leishmania braziliensis. Infect Immun (2005) 73(9):5827-34. doi:10.1128/IAI.73.9.5827-5834.2005

Conflict of Interest Statement: The authors declare that the research was conducted in the absence of any commercial or financial relationships that could be construed as a potential conflict of interest.

Copyright (C) 2015 de Mendonça, Cysne-Finkelstein and Matos. This is an open-access article distributed under the terms of the Creative Commons Attribution License (CC $B Y)$. The use, distribution or reproduction in other forums is permitted, provided the original author(s) or licensor are credited and that the original publication in this journal is cited, in accordance with accepted academic practice. No use, distribution or reproduction is permitted which does not comply with these terms. 